\title{
Planes of Communicative Activity in Collaborative Writing
}

Ian Thompson

University of Oxford

If one changes the tools of thinking available to a child, his mind will have a radically different structure. (Vygotsky 1978, p.126).

\begin{abstract}
:
In this article I focus on the mediational role of communicative activity in the co-construction of meaning involved when pupils write collaboratively. I explore the developmental nature of peer intermental or social activity within a ZPD by drawing on perspectives from sociocultural theory and the dialogical aspects of some classroom activity. Vygotsky's concept of the Zone of Proximal Development (ZPD) is viewed as a tool used to produce forms of instruction that lead pupils' psychological development. I identify three planes of communicative activity relating to physical, semiotic and intrapersonal tool usage in order to develop an analysis of two secondary school pupils involved in the shared activity of producing a co-constructed text.
\end{abstract}

\section{Mediation in the Zone of Proximal Development}

In this article I want to address the question of how pupils involved in a shared activity appropriate and internalise the cultural tools that aid their psychological development from verbal dialogue to inner speech and in turn to written speech. What are the forms of communication and activity involved in the semiotic creation of meaning when writing collaboratively? Bruner $(1971,1986)$ argues that the child needs to make knowledge its own within a shared culture of learning. Children learn not only through discovery and invention but also by negotiating and sharing. Education is not the mere learning of specific knowledge or skills but the development of children's learning abilities: their ability to think both logically and creatively; the capacity to plan and act on those plans; and the ability to communicate their understanding both through speech and writing (Hardcastle 2007; Thompson 2012).

A central part of the teacher's role is to help provide their pupils with a set of cultural tools for thinking and creating. Vygotsky's concept of the Zone of Proximal Development (ZPD), 'the difference between the level of solved tasks that can be performed with adult guidance and help, and the level of independently solved tasks', provides teachers with the theory for effective practice (Vygotsky, 1978, p.86). Vygotsky (1986) argues that full development 
through the ZPD depends upon full social interaction with peers and mediators (such as adults) and the sociocultural importance of sign systems. Moll summarises the centrality of mediation to learning as follows:

To put it simply, human beings interact with their world primarily through mediational means; and these mediational means, the use of cultural artefacts, tools and symbols, including language, play crucial roles in the formation of human intellectual capacities. (Moll, 2000, p.257)

Vygotsky viewed the ZPD as a tool for academic and psychological assessment that could lead to instruction that leads the development of mental processes through mediated activity (Wertsch, 1985). Vygotsky's focus is therefore on the child's maturing psychological functions and teaching that is directed at emerging higher order processes.

\section{Dialogue, Communicative Activity and the ZPD}

So what are the types of social interaction that lead to development in a ZPD when children write collaboratively? As Moll (1990) states, ZPD analysis should focus on the 'nature of social transactions' (p.11) in classroom discourse. Newman, Griffin and Cole (1989) use a broad definition of the ZPD as being an interactive system within which at least one of the participants could not work effectively on their own. Following Leontiev (1981) they see the acquisition of knowledge within a ZPD as being one of appropriation:

Cognitive change takes place within this zone, where the zone is considered both in terms of an individual's developmental history and in terms of the support structure created by the people and cultural tools in the setting. Methodologically, cognitive change can be observed as children pass through or work within the zone. (Newman et al., 1989, p.61)

The ZPD then becomes a tool that focuses teachers and researchers both on the activity that leads to mastery of the task by the child and also on the kind of help that needs to be provided for the cognitive change to occur.

With reference to activity, Mercer (2000) points to dialogue within a ZPD as a dynamic frame of reference through which the teacher, or another pupil, helps the pupil towards a shared understanding of the tasks in which they are engaged. Reed (2005) develops the concept of dialogic activity based on both Bakhtin's (1981) view of utterances as coconstructed activity as well as Habermas' (1985) concept of ideal speech whereby 
participants in a dialogue have equal status in a dialogue designed to produce consensus or agreement.

After Habermas, Reed (2004, 2005) identifies three communicative worlds in classroom activity, which correspond to different levels in the analysis of mediation identified by Vygotsky: material tools, psychological tools and the role of other people, the subjective world of the learner (Cole 1996; Beattie, 2007):

- The external and objective world. This includes the effects of physical tool usage and the physical environment as well as the objective purpose and achievements of task.

- The social world. The use of sign systems and semiotic resources as tools, conventions of social and cultural practices and interactions with others.

- The subjective world. The deployment of psychological feelings, imagination and self-histories.

Of course these communicative worlds are not divorced from each other and all are in play for learners at the same time. The objective world of physical tool usage and task achievement is influenced by the social world of sign usage and dialogical discourse, as well as by the subjective world of the learner's history. What ties these worlds together is the central activity of making meaning through language.

In the following analysis I will use the term planes of communicative activity as a method of highlighting specific forms of mediation within the overall activity of collaborative writing. These planes correspond to the distinctions that Reed noted from Vygotsky between physical tool usage, semiotic tool usage and the intrapersonal world of the learner. Within the act of shared writing, planes of communicative activity may be defined, as follows:

- Physical activity: the use of writing tools, composition, task completion.

- Interpersonal semiotic activity: dialogue with others, the use of sign systems, task understanding.

- Intrapersonal activity: the affective, personal and social histories, task enjoyment. 
So how do these planes of communicative activity function in the collaborative construction of a text? By setting a collaborative writing task the teacher can create the potential for dialogical activity as pupils negotiate meaning. Yet as Tudge (1990) points out simply pairing pupils of differing ability does not guarantee development. Rather, it is through complex processes of semiotic interaction involved in collaborative activity that pupils develop the psychological tools required to appropriate the cultural significance of language. In what follows, I explore the social activity of collaborative writing. Through observation of the forms of communication involved, I seek to trace the movement between material tools, the interpersonal world of communicative activity, and the intrapersonal level of inner speech, through to the abstract form of symbolising that is writing.

\section{The Social Context of Collaborative Writing}

The case study presented in this article is drawn from video data of two Year 9 (ages 13-14) English lessons that I taught in a computer suite in a comprehensive school in 2004. The analysis concentrates on the communicative activity of two pupils, Dan and Tim, as they negotiate and complete a text through collaborative writing.

Dan and Tim were socially confident and integrated members of their class. However, weaknesses in written expression were hindering their progress. Tim in particular rarely redrafted his written work. My written comments on how to improve his work were consistently ignored. In fact Tim frequently destroyed his written work when frustrated by the process of composition. Dan, on the other hand, did sometimes attempt to redraft, following suggestions, but in practice his attempts to improve his text usually amounted to simple technical corrections of spelling and punctuation errors.

For both boys then the procedures that they had developed for writing were at best tortuous and at worst an impediment to composition. Nevertheless, Dan and Tim were confident orally and strong friends. Despite their weaknesses in writing, they both particularly enjoyed writing on computers in English lessons and chose to work together at every opportunity. These facts suggested that Dan and Tim would have the confidence and trust in each other essential to successful collaborative working and the ability to articulate their thoughts within their shared discourse. 
The task that I had devised for the class involved pairs working on adjacent computers writing a horror story with parallel narratives that were to be discussed and incorporated into a dual narrative. The context of the computer suite in creating the conditions for dialogue in collaborative writing was important. As Wertsch emphasises, the introduction of a new cultural tool such as a computer word processor for a pupil can lead to a 'qualitative transformation of that action rather than a mere increment in efficiency or some other quantitative change' (Wertsch, 2002, p.105). Here, the computer served as a physical tool for manipulation of text and was also an integral part of a situated and culturally mediated activity, involving for both pupils and teachers their past and present experiences of writing (Somekh, 2007; Wertsch, 2002).

\section{Planes of Communicative Activity}

The story of the boys' successful collaboration towards their completed text can be summarised as a sequence in which they moved from uncertainty and resistance into a consolidating and supportive relationship, and finally to the creative fulfilment of the task. The sequence involved the boys working within a shared or reciprocal ZPD where at various points, and with some role reversal, each acted developmentally as a significant other for his fellow pupil. This development involved all three planes of communicative activity throughout this sequence, although at times one of these planes of communicative activity was more evident and therefore more significant as the focus of research analysis. The other planes of activity might be concealed by the priority activity but were nevertheless still integral to the process of developing collaboration.

The initial exchanges between Dan, Tim and myself as the teacher were illustrative of this layering of communicative activity. Tim's spoken discourse began by concentrating on perceived technical failures of his computer. The computer, in Tim's words, was "mucked up", implying that technical problems prevented him from starting work. In fact it became evident from watching Tim's actions that the computer problems were mainly caused by Tim looking for evasive tactics, suggesting a retreat into his emotional past history with computers. As soon as I came over to talk to Tim and to ask him if his computer is working he said that it "might do it now". He then turned the computer and screen on. Even when Tim's computer had been correctly started he did not look at it but instead concentrated on Dan's screen. Dan, on the other hand, had clearly assimilated the information from the 
modelling session in the early part of the lesson. He was able to relate his previous knowledge of narrative structure with the initial task of developing an overall framework for his part of the story and showed a clear sense of task direction.

During the initial interaction, Dan appeared to be unwilling or unable to draw Tim into the work and his responses to Tim were terse as he concentrated on his own ideas. However, Tim continued to engage in dialogue with Dan and watched him as he wrote on screen. As the lesson proceeded, the boys gradually developed their ability to work collaboratively and dialogically. They drew on their past experiences of the semiotic conventions of the genre of psychological thriller or murder story in order to develop a collaborative script. In this sequence it was apparent that Tim grew in confidence as he helped Dan to develop their shared plan. The pair established a system of mutual questioning and at times one of the boys finished the other person's sentence. These instances were characterised by incomplete sentences, muttering, repetition and questions directed both at the other and self. The activity represented a distinct form of semiotic engagement as the boys collaboratively negotiated meaning through gesture linked to incomplete verbal utterances. They developed a shared method of articulating the ideas formed through their separate inner speech. This essentially egocentric speech underpinned the social function then developed in the plane of semiotic activity.

Tim's hesitation to use the computer as a writing tool was overcome through the semiotic activity involved in the boys' shared use of the computer. The computer as a cultural artefact and tool bridged both the physical activity of task and the psychological activity of drawing on past histories.

\section{Appropriation and Development}

In the following sections I present episodes and descriptions from the video data of Dan and Tim working collaboratively in the ZPD in order to demonstrate the interaction of the three planes of communicative activity. While it is the spoken interchanges between the pupils that that will be foregrounded in my presentation, I will draw also on the evidence derived from gesture and from physical action, which is made available through the video recordings. 
In Episode 1 Dan appears now to be acting as a significant other for Tim, while both are also drawing on their semiotic tool-kit of sign conventions used in the social world. Dan repeats his thoughts (egocentric speech) as he attempts to verbalise the planning process. His verbalisation of his inner speech shows the forming of the concept that the story will be about a "murder". At the same time, he is becoming inclusive in his treatment of both the task and his writing partner in the plane of social semiotic activity.

\section{Episode 1}

Dan: We need a name for this thing. Um. What are we calling it?

Tim: Um. Dunno.

Dan: "It's got to have something with murder in it. It's got to have something with murder in it. You're a murderer. It's got to have a murder in it. It's got to have s..."

Tim: Something with a murder in it. A Big Murder Loss (laughs).

This is the first point in the data that Tim refers directly to the task and the genre. Tim also becomes physically involved as he leans across Dan to type his title "A Big Murder Loss." Both are clearly thinking in this sequence. Their gestures, as they pull faces at each other and point, suggest that they are on the edge of saying something important. In this exchange Dan remains focussed on the screen and although he briefly addresses Tim it is clear that Dan has started to use the computer as a tool for writing. For Dan, activities in both the semiotic and physical communicative planes overlap and intertwine at this point. Meanwhile, the physical relationship between the boys and the computer is illuminating, as they form a triangle with the keyboard as they both type as well as with the computer screen as they look up. The boys' physical action as they type together represents their use of the body as a tool: gesture and manual action are means for the boys to respond and use the cultural artefact of the computer and the physical environment of shared activity of collaborative writing.

In this sequence we can see how the boys develop their ability to work collaboratively and dialogically. They draw on their past experiences of the semiotic conventions of the genre of psychological thriller or murder story that they are soon to develop in their collaborative script. This instance represents a distinct form of semiotic engagement as the boys collaboratively negotiate meaning through gesture linked to incomplete verbal utterances. They develop a shared method of articulating the ideas formed through their separate inner speech. This initially egocentric speech is then transformed through social interaction in the plane of semiotic activity. 
My intervention in as a teacher in Episode 2 introduces a new dimension of semiotic activity with the boys. Initially, I have incorrectly assumed that the boys are not on task. Apart from the instructions to make a series of bullet points and to think about the title at a later point the rest of my discourse consists of a series of questions aimed at Dan. The aim of the questioning is to focus Dan on the narrative through the question what happens next? Finally, the lack of response prompts me to make the suggestion framed in the form of a question that becomes central to Tim's version of the narrative.

\section{Episode 2}

Mr T: So what's the first point? What happens? (Pause to wait for response)

Dan: I don't know what happens. Oh I know.

Mr T: Make yourself a list... Right... Bullet points.

So what happens? (Reads Dan's notes) Something about a murder? (Pause) Is someone found murdered? Dan: Err. Yeah (emphatic).

My instructional talk is at a basic task level ("make yourself a list") and I do not consciously engage the boys at this point within their shared ZPD. However, the effect of this intervention is that Dan develops the collaborative writing process and Tim becomes involved for the first time in the task. The intervention helps the boys on different levels. Dan is assisted on the level of direct instruction whereas Tim is helped on the assisted performance levels of reassurance and redirection. However, the importance of the semiotic mediation described is that both boys now begin to work towards the semiotic agreement required by their collaborative task and within their reciprocal ZPD. My argument here is that the assistance becomes transformational for the boys' performance as they negotiate shared meaning within their collective ZPD. At this point social interaction takes on a potentially transformative role.

After this intervention, Tim initially takes the lead in the discussion between the pair. My questioning of Dan has acted indirectly as a catalyst for the thoughts of Tim shown by his gaze and attentive listening as he watches the screen. Dan, on the other hand, enters a short period of passivity that soon develops into system of mutual questioning that is to become the key part of their collaboration. From this point the boys act as equals as they negotiate their shared points until Dan finally reasserts his dominance over the decisions. As can be seen in episode 3 , the discourse between the pupils in this sequence has a dialogic and equal quality 
and both boys have become active agents in the appropriation of their learning as they work towards reaching normative agreement within their shared ZPD.

\section{Episode 3}

Tim: So we do a plan together.

Dan: And we can do now we can do... Something like...

Tim: Um now we can do... a list... points. Write down a murder, murderer, a druggie murder. Who does he kill? And police.

Dan: Yes I get it.

Tim: He could kill someone...someone he knows. A mistake. A murder mistake.

Dan: Yes I get it. A mistake. A killer.

Although by the end of this sequence the boys have negotiated the bullet points they intend to use for their writing plan, it is also important to note at this stage that this does not become a rigid framework but in fact constitutes a frame of reference, or mutual sign system, that they use to recall previous ideas as they write. For example, at least two ideas of Tim's are rejected by Dan and do not appear in the bullet point plan.

However, when they begin to write their narratives both these ideas return. The bullet points created by the boys in practice constitute semiotic signposts that allow Tim in this case to recall his previous cognitive processes. At this stage the bullet points for Tim do not represent a fully constituted text, or what Vygotsky calls the higher forms of written language, but instead function as second-order symbols where 'written symbols function as designations for verbal' (Vygotsky, 1978, p.116). The appropriation and use of these symbols are the 'linguistic and textual resources' that pupils use as they master the conventions of written speech through semiotic activity (Reed, 2004, p.36)

\section{Collaborative Activity and the Affective}

So what of Dan and Tim's own histories and imagination? Where do they position themselves in the emerging collaborative text? How do these affective factors relate to their communicative activity? As the boys collaborate through the combination of physical, psychological and semiotic activity they attempt to negotiate shared meaning. Visual analysis of the data suggests a relational change (Edwards, 2005; Edwards and D'Arcy, 2004) has taken place whereby Dan and Tim now act as mediators for each other within the plane of psychological activity. For example they direct their gaze to the screen and not each other as they collaborate. They draw on their mutual histories as learners in a positive sense as 
opposed to their previous experience of failure. This relational change is important for the boys for two key reasons:

1. Their positive feelings and imagination can now become a tool within their collective activity.

2. Their joint activity as mediators means that they maintain a sense of collaborative well-being and mutual support.

Both boys during this discussion suggest their psychological reluctance to tackle the extended writing that constitutes the next phase of the task. The psychological feeling of frustration that both boys have experienced in their histories of writing clearly has an influence on the ways both they perceive themselves as writers. Without overcoming this mental block written progress will remain difficult. Dan most graphically articulates this when he describes having to write six paragraphs as being "six punches of hell". When I asked Dan subsequently what he meant by this phrase as a writer he replied:

I find it hard to get my ideas out sometimes. I mean I know what I want to say but I just can't say it if you know what I'm saying. It is just hell.

Tim, on the other hand, at this point expresses his own psychological history as a writer when he states that the bullet point plan is necessary for them to be able to create more than one paragraph of text.

Tim's recollection of the semiotic tool of the bullet point enables him to complete the physical activity of task. My experience of Tim's previous efforts at composition is that without a plan he would incorporate several undeveloped ideas into one paragraph. Significantly, Dan responds to this moment of crisis by deleting two bullet points and then rewriting them jointly with Tim. Their joint communicative activity shows that collaborative talk and action can function as a tool for learning, as the pupils 'take over the culture's toolkit of skill, knowledge and values' (Wells, 1999, p.335). The fact that they now go on to successfully write a collaborative text also suggests that their affective response to writing has altered through communicative activity.

\section{Collaborative Composition}


The final act of composition can be characterised in this case as a process of movement from the inner speech created by dialogical relations of collaboration through communicative action towards the abstract form of language that constitutes writing. Inner speech, in terms of communicative activity, constitutes the incorporation of all three planes of communicative activity into the internal development of moving from interpersonal to intrapersonal activity. It is through inner speech, the 'bearer of experience', that pupils develop the advanced mental concepts used for writing (Britton, 1992, p.155). As Dan and Tim wrote their part of the shared composition they built on the shared agreement that they have developed through the three planes of communicative activity.

In a closing episode 4, the boys comment on the final version of their text. Both boys had read their partner's work and Tim had imported his text into Dan's machine. Once Dan had both texts available he quickly and confidently ordered them into what became the final text. The speed of this process suggests that Dan not only recalled the process modelled by myself and another pupil in a previous lesson but that he had already considered the order of the final text. This suggests a developmental change in his ability to process abstract thought. Tim appeared happy to allow Dan to take the lead in this part of the work but he too in this episode claims ownership of the finished text.

\section{Episode 4}

Tim: Looks good. Hey you used my suicide bit. Heh. That's good innit? (two second pause) Sorted.

Dan: Is it enough? Is it all right do you think?

Tim: I don't care. I like it. It's good I think.

Dan: Yeah. Looking good. Great.

Both Tim and Dan have developed both their ability to write collaboratively and also their confidence in themselves as writers. Their faces in this sequence express both satisfaction and pride at their efforts. The final text is reproduced in full below:

\section{Family Murder \\ It was dark. Very dark. I hadn't eaten for days and my skin was itching. I had to get a score soon or my mind would rot.}


Then I saw her. I didn't stop to think. I ran after her. She turned and screamed and nearly got away. Something inside me made me run faster. "

"Now I've got you." I laughed.

"Get off me!" she screamed.

"Give me your purse and everything else you have. I've got a gan."

This is the BBC news. A fifteen year old girl was found murdered in Bath today. 'The police have arrested several suspects but say they all deny doing it. 'The police are continuing their inquiries and ask everyone to stay calm.

The gun was hot in my hand. It had gone off. I had shot her. She lay on her side in a pool of blood. Dead. I had to act quick. I grabbed her purse and phone from her bag and pulled off her watch. I nearly took her trainers but they looked old. I didn't think about her just the things she had. I hid the body in an alley and walked away.

Poppy Davies was watching telly. She had worked that morning at Sainsburys and she was tired. 'The news came on. Not another kid killed she thought. Why do their mothers let them out? Suddenly, there was a knock and the door. It was the police and they looked sad.

At home I looked through the purse and found $£ 25$. Enough to get some drugs. When I had got them I stopped shaking. I was calm. I could think. When I looked in the purse I found the girl's ID. I stared at it. Daisey Davies. She had the same second name as me. It couldn't be could it? I used her phone and found the contact called Mum. I tried it and it went to the answer phone. It was my sister's voice. I had killed my own niece. I felt sick. I had to tell my sister what I had done.

When the police finally left Poppy just cried and cried. She couldn't believe it. Her daughter dead. When the phone went she didn't answer. Then the door went. She looked through the window. It was her brother. She had not seen him for years. Not since he stole her money to buy drugs.

I didn't know how to start. I wanted to explain but what could I say? Then I just told her. Just like that, straight out. I told her I would change. I would try to make Daisy's life worthwhile. She just screamed at me. She said she was going to tell the police. I couldn't face going back inside. I had to run. 
This is the BBC news. The police have announced that they have a new suspect for the murder of young Daisy Davies. It is her uncle Dave Davies and they believe he is on the run. The police say he is armed and dangerous and should not be approached,

I am writing this letter to say sorry to Daisy, my sister and anyone else I have hurt. I can't go on living knowing what I have done.

Dave Davies RIP

\section{Interpretation of Case Study}

This case study provides an example of pupils developing their ability to write through the collaborative and dialogical activity represented in the three planes of communicative activity. Dan and Tim's increased confidence as writers had developed from peer interaction within their shared ZPD. The final text produced by Dan and Tim is in many ways a triumph of collaboration both between the boys and through their dialogue with their teacher. The contrast between the two narrative voices is highly effective. In the plane of physical activity the students have achieved their task through an effective and inventive deployment of physical tools and resources. In the plane of semiotic activity, Dan's paragraphs use a range of sentence structure to create the appropriate tension within the first person narrative of the murderer. Tim in fact uses two narrative voices: the impersonal tone of the BBC newsreader reportage contrasts with the tone of the omniscient narrator of his other paragraphs. He has successfully incorporated the register and tone of both narrative techniques. The text is both collaborative in its constituent parts of the two narratives but also in the negotiations of meaning that have taken place between the learners. It is significant in the plane of affective psychological activity that both the boys took pride in this piece of work.

The forms of communicative action evident within their collaborative activity can be said to foreground adult independent work practices. Of course it would be wrong to argue that Dan and Tim were now expert writers but it would be true to say that each had made significant progress in their ability to compose texts through collaborative and communicative activity. Each boy had been integral to the production of a significant completed narrative text that addressed an audience and communicated meaning. They had succeeded as writers. 
So what had changed and how had this happened? I would argue that the case study reinforces Vygotsky's view that the most powerful aspects of learning take place when pupils are working within ZPDs and are engaged in dialogical activity. In this article I have used the planes of communicative activity as a tool to analyse both the process of written composition and as a means of responding to the final collaborative text of Dan and Tim. Indeed both the ZPD and planes of communicative activity are revealed by attention to the specific tool usage (physical, semiotic and feelings) of the agents involved. Dan and Tim were able to find solutions to their collaborative task by drawing on their semiotic tool-kit consisting of a whole range functional tools and signs or psychological tools that act as semiotic mediation.

In Dan and Tim's case this process of mediated activity through communication involved psychological communicative activity through their own previous histories as writers both in positive and negative senses, physical activity with the computer as a functional tool for writing, and semiotic activity in the social world of the classroom through dialogue between the boys and with other learners as well as their interaction with their teacher. Successful collaborative writing is based on dialogue about, and around, the composition or construction of the text. This co-construction of meaning is both a dialogical cultural phenomenon and intrinsically connected to the social context of the classroom.

\section{References}

Bakhtin, M. 1981. The Dialogic Imagination: Four Essays. Austin: University of Texas Press.

Beattie, A. 2007. 'Exploring the Value of Dialogue in Improving Boys' Writing.' Changing English 14, no.2: 161-174.

Britton, J. 1992. 'The Anatomy of Human Experience: The role of inner speech.' In New Readings: Contributions to an Understanding of Literacy, eds. K. Kimberley, M. Meek, M. and J. Miller, 146-156. London: A \& C Black.

Bruner, J. 1971. The Relevance of Education. New York: Norton.

Bruner, J. 1986. Actual Minds, Possible Worlds. Boston: Harvard University Press.

Cole, M. 1996. Cultural Psychology. Cambridge, MA: Harvard University Press.

Edwards, A. 2005. 'Relational Agency: Learning to be a Resourceful Practitioner.' International Journal of Educational Research, 43:168-182.

Edwards, A. and C. D'Arcy. 2004. Relational Agency and Disposition in Sociocultural Accounts of Learning to Teach.' Educational Review, 56, no.2: 147-155. 
Habermas, J. 1985. The Theory of Communicative Action. Boston: Beacon Press.

Hardcastle, J. 2007. 'Explaining the Actions of Men and Gods: Elements of English Pedagogy.' Pedagogy, 7: 453-480.

Leontiev, A. N. 1981. Problems of the Development of Mind. Moscow: Progress Publishers.

Mercer, N. 2000. Words and Minds: How We Use Language to Think Together. London: Routledge.

Moll, L. 1990. 'Introduction.' In Vygotsky and Education: Educational Implications and Applications of Educational Psychology, ed. L. Moll, 1-30. New York, NY: Cambridge.

Moll, L. 2000. 'Inspired by Vygotsky. Ethnographic Experiments in Education.' In Vygotskian Perspectives on Literacy Research: Constructing Meaning Through Collaborative Inquiry, eds. C. Lee and P. Smagorinsky, 256-268. Cambridge: Cambridge University Press.

Newman, D., P. Griffin, and M. Cole. 1989. The Construction Zone. Cambridge: Cambridge University Press.

Reed, M. 2004. 'Write or wrong? A Sociocultural Approach to Schooled Writing.' English in Education, 38, no.1: 21-38.

Reed, M. 2005. 'Strong Language, the Purpose of Dialogue in the Development of Writing.' Changing English, 12, no.1: 85-102.

Somekh, B. 2007. Pedagogy and Learning with ICT. London: Routledge.

Thompson, I. 2012. 'Stimulating Reluctant Writers: A Vygotskian Approach to Teaching Writing in the Secondary School.' English in Education, 46 no.1: 84-91.

Tudge, J. 1990. ' Vygotsky, the Zone of Proximal Development, and Peer Collaboration: Implication for Classroom Practice.' In Vygotsky and Education ed. L. Moll, 155-174. Cambridge: Cambridge University Press.

Vygotsky, L. S. 1978. Mind in Society. Boston: Harvard University Press.

Vygotsky, L. S. 1986. Thought and Language. Cambridge, MA: MIT Press.

Wells, G. 1999. Dialogic Inquiry: Towards a Sociocultural Practice and Theory of Education. Cambridge: Cambridge University Press.

Wertsch, J. V. 1985. Vygotsky and the Social Formation of the Mind. Cambridge MA: Harvard University Press.

Wertsch, J. V. 2002. 'Computer Mediation, PBL and Dialogicality.' Distance Education, 23, no.1:105-108. 